\title{
RENTABILIDADE EFETIVA E RENTABILIDADE TOTAL DO CULTIVO DE MILHO ADUBADO COM LODO DE ESGOTO
}

\author{
QUINTANA, Núria Rosa Gagliardi ${ }^{1}$ \\ MELO, Wanderley José de ${ }^{2}$ \\ CARMO, Maristela Simões do ${ }^{3}$
}

\begin{abstract}
RESUMO: Este trabalho teve como objetivo calcular as rentabilidades efetiva e total do cultivo de milho adubado com lodo de esgoto. O experimento, cuja produtividade média foi de $375,38 \mathrm{~kg}$, foi instalado no ano agrícola 2002/2003, em Latossolo Vermelho eutroférrico e conduzido com milho AGROMEN 3150, através de cultivo mínimo. A dimensão da área experimental estudada foi de $625 \mathrm{~m}^{2}$. As operações de cultivo foram detalhadas para especificar máquinas, equipamentos, mão-de-obra, insumos consumidos e horas trabalhadas. Os custos operacionais, calculados conforme a metodologia do IEA, foram subtraídos da receita, resultando nas rentabilidades. Os resultados de rentabilidade efetiva $(\mathrm{R} \$ 55,80)$ e total $(\mathrm{R} \$ 40,70)$ apontam que a aplicação de lodo de esgoto é economicamente rentável.
\end{abstract}

Palavras - chave: Custo de produção. Biossólido. Fertlização.

SUMMARY: In this study, we calculated effective and total economic rentability about corn production fertilized with sewage sludge. The corn was cultivated on a minimal tillage treatment in a field experiment. The trial was carried out during 2002/2003, set up on an oxisol area of $1 / 16$ ha The farming operations were detailed to specify machinery, equipment, manpower, materials consumed and hours worked. Operating costs, calculated accordingto the methodology of the IEA, were subtracted from revenues, resulting in profitability. Results indicate that the application of sewage sludge is economically profitable.

Keywords: Production cost. Biosolid. Fertlization.

\section{INTRODUÇÃO}

Rentabilidade econômica é a diferença entre receita e custos de produção.

A análise do custo de produção para determinação da eficiência econômica é fundamental no estudo de rentabilidade dos recursos utilizados (REIS; TAKAKI; REIS, 1999), auxiliando os agricultores na tomada de decisão (REZENDE et al. 2005). Espera-se que o preço de venda cubra no mínimo o custo de produção e, além disso, possibilite um lucro.

Caso o custo de produção seja maior que o preço da mercadoria, cabe análise detalhada de como os fatores fixos podem estar elevando o custo e reduzindo a receita, cuja remuneração no curto prazo, muitas vezes, o empresário não leva em consideração para o planejamento do empreendimento e eleição de algumas entre todas as opções de exploração (MATSUNAGA et al., 1976).

A disposição agrícola do lodo de esgoto é vantajosa aos agricultores, na medida em que reduz os custos de produção e mantém a produtividade da lavoura. (TRANNIN; SIQUEIRA; MOREIRA, 2005).

Os elevados teores de matéria orgânica, além dos macro e micronutrientes existentes no lodo de esgoto, permitem-no ser comparado a um biofertilizante potencial, capaz de proporcionar outros efeitos

\footnotetext{
${ }^{1}$ Faculdade de Ciências Agronômicas/Universidade Estadual Paulista

2 Engenheiro Agrônomo, Professor Titular do Departamento de Tecnologia, Faculdade de Ciências Agrárias e Veterinárias (FCAV) da Universidade Estadual Paulista (UNESP).

${ }^{3}$ Engenheira Agrônoma, Professora Adjunta do Departamento de Gestão e Tecnologia Agroindustrial, Faculdade de Ciências Agronômicas (FCA) da Universidade Estadual Paulista (UNESP) e Professora Colaboradora da PósGraduação da FEAGRI/UNICAMP.
} 
benéficos ao solo que não acontecem com a adição dos adubos químicos.

Embora existam na literatura várias contradições em relação ao efeito do lodo de esgoto sobre as características do solo e a disponibilidade de nutrientes às plantas (GUEDES et al., 2006), muitos autores ressaltam o benefício da aplicação do lodo no desenvolvimento da vegetação, além da recuperação de solos (BEZERRA et al., 2006).

Lemainski e Silva (2006) afirmam que o aproveitamento do lodo de esgoto como fertilizante na cultura da soja é viável tanto em termos agronômicos como econômicos.

Dessa forma, a reciclagem agrícola dos lodos de esgoto destaca-se como forma de reduzir a pressão sobre a exploração dos recursos naturais, além de evitar destino final de custos elevados e de maior impacto no meio ambiente (ANDREOLI; LARA; FERNANDES, 1999).

Este estudo propõe o cálculo da rentabilidade efetiva e da rentabilidade total do cultivo de milho adubado com lodo de esgoto como forma de avaliação do desempenho da cultura conduzida com esse biofertilizante.

\section{MATERIAL E MÉTODOS}

A área cultivada localiza-se na Fazenda de Ensino e Pesquisa da Faculdade de Ciências Agrárias e Veterinárias (FCAV) da UNESP, Campus de Jaboticabal, SP. O experimento foi instalado durante o ano agrícola 2002/2003, utilizando-se Latossolo Vermelho eutroférrico e conduzido com a cultura do milho híbrido duplo AGROMEN 3150.

Adotou-se o sistema de cultivo mínimo, onde foram feitas aplicações de herbicida dessecante 20 (vinte) dias antes da data prevista para semeadura. Em seguida, somente a camada superficial do solo (0$15 \mathrm{~cm}$ ) sofreu gradagem leve. Após a primeira gradagem, ocorreu distribuição do lodo de esgoto nas parcelas, incorporado através de nova operação de gradagem.

O lodo de esgoto proveniente Estação de Tratamento de Esgotos de Barueri, que é gerenciada pela SABESP, foi obtido por tratamento com polímero. Destaca-se que este resíduo possui alto teor de umidade em sua composição.

A matriz econômica foi montada de acordo com o modelo de custos de produção adotado pelo Instituto de Economia Agrícola (IEA) da Secretaria de Agricultura e Abastecimento do Estado de São Paulo.

Este modelo propõe a descrição de todas as atividades de cultivo, desde o preparo do solo até a colheita, detalhando os tipos de máquinas e implementos utilizados, mão-de-obra aplicada, tempo de duração de cada uma destas atividades, e ainda, quantidade dos insumos consumidos.

Os preços de cada item de despesa assinalada foram aplicados às quantidades obtendo-se os custos de produção. Além destes itens, acrescentaram-se ainda nestas matrizes, dados de receita e rentabilidade.

Basicamente doze operações de cultivo compuseram o itinerário técnico de produção do milho: aplicação de herbicida; rebaixamento vegetal; gradagem leve; aplicação de lodo de esgoto; gradagem leve; sulcamento; adubação mineral; semeadura; desbaste; aplicação de herbicida; aplicação de inseticida e colheita mecanizada.

É importante ressaltar que, de acordo com o modelo utilizado, os coeficientes técnicos de produção são expressos em quantidade utilizada por hectare. No entanto, por se tratar de área experimental, com $625 \mathrm{~m}^{2}$, optou-se pela montagem da tabela nessas dimensões, a fim de evitar possíveis erros de distorção ao se expandir os dados para um hectare, base geralmente usada em cálculos de custo de produção e rentabilidade. 
Para os cálculos do custo de produção e rentabilidade de cada matriz foram utilizados os preços vigentes no mercado nos anos agrícolas correspondentes.

Como o lodo de esgoto, atualmente, é doado aos produtores com interesse na sua utilização, considerou-se que a aquisição deste material não teve nenhum custo na realização do experimento. Com o emprego do programa Excel foram obtidos os custos operacionais, conforme a metodologia (MATSUNAGA et al., 1976). Nessa estrutura, os custos totais são divididos em custo operacional efetivo (COE) e custo operacional total (COT), considerando os gastos variáveis e parcelas dos gastos fixos, deixando para os prováveis resíduos positivos (receita menos custos) a remuneração de outros fatores de produção como o lucro sobre o capital empregado, a renda da terra e o trabalho gerencial do empresário.

Com isso, é possível eliminar distorções que conduzam à inviabilidade do agricultor no curto prazo, uma vez que o COE engloba os gastos efetivamente desembolsados pelo agricultor, correspondendo aos custos variáveis, entre eles despesas com mão-de-obra, operações com máquinas e equipamentos e material consumido.

Ao COE são acrescentadas parcelas dos custos fixos relativas à depreciação de máquinas e equipamentos, e juros sobre capital investido, compondo o COT, de tal forma que o agricultor torna sua produção viável no curto prazo quando o preço do produto é maior (ou igual) ao custo operacional efetivo médio.

\section{Cálculo do Custo Operacional Efetivo}

O Custo Operacional Efetivo consiste na soma dos valores de custo horário de operação e material consumido.

\section{- Custo Horário de Operação}

O total de horas trabalhadas pelos tratoristas e diaristas (Relatório Convênio, 2001) foi multiplicado pelos preços correntes, obtidos junto à Casa da Agricultura de Jaboticabal.

Para calcular o custo horário de operação das máquinas e equipamentos, multiplicaram-se as horas de uso pelo custo horário, sem depreciação, calculado pelo IEA, e disponível na Revista Informações Econômicas do mês de março de 2003. De acordo com esta publicação, o custo horário sem depreciação inclui garagem, reparos, combustíveis, lubrificantes, pneus, e seguro para tratores, colhedoras e caminhão.

\section{- Custo de Material Consumido}

O custo com material consiste no produto da quantidade utilizada pelo preço vigente no mercado durante o período em que o insumo foi consumido. Da mesma forma que no item anterior, esses preços foram obtidos junto à publicação do IEA. Em alguns casos, quando o material não constava da lista disponibilizada, os preços foram levantados em lojas no município de Jaboticabal e foram corrigidos pelo índice IGP-M da Fundação Getúlio Vargas.

\section{Cálculo dos Custos Operacionais Totais}

O COT representa o COE acrescido de parte dos custos fixos, como a depreciação de máquinas e equipamentos.

\section{- Depreciação de Máquinas e Equipamentos}

É o produto da hora de uso dos equipamentos, em cada atividade, pela depreciação horária 
calculada pelo IEA, disponível na Revista Informações Econômicas.

\section{- Juros sobre Capital Investido}

Embora este item não faça parte da metodologia de cálculo de custos adotada pelo IEA, optou-se por incluí-lo neste trabalho a fim de possibilitar que o custo de produção cubra o custo de oportunidade.

Os juros correspondentes ao uso das máquinas e equipamentos podem ser obtidos pela fórmula sugerida pelo IEA: $((\mathbf{C} \mathbf{0} / \mathbf{2}) * \mathbf{r}) / \mathbf{U A}$

Onde: $\mathbf{C} 0$ é o preço do equipamento novo; $\mathbf{r}$ é a taxa de juros, aqui considerada 0,12 (12\% ao ano); e UA é horas de uso anual. Os dados de custo inicial dos equipamentos foram retirados das publicações da Revista Informações Econômicas.

\section{Cálculo de Receita e Rentabilidade}

Multiplicou-se a produtividade média pelo preço do milho no mercado, para o mês de abril de 2003, publicado em Informações Econômicas, relativo ao Escritório de Desenvolvimento Rural que engloba o município de Jaboticabal (EDR de Jaboticabal).

Assim como os custos de produção, as rentabilidades foram chamadas de Efetiva e Total. A primeira consiste na diferença entre a Receita e o COE, e a segunda, na diferença entre a Receita e o COT.

\section{RESULTADOS E DISCUSSÃO}

Os dados de operações, mão de obra, máquinas e equipamentos e horas trabalhadas, estão expressos na tabela 1. Através dessa tabela é possível afirmar que naquele ano agrícola houve a necessidade de aplicação de herbicida e inseticida, além de adubação mineral complementar.

TABELA 1 - Coeficientes Técnicos e Custo Horário de Operação do Milho de Verão, Preparo Reduzido de Solo, Experimento instalado no ano agrícola 2002/2003 na Fazenda de Ensino e Pesquisa da Faculdade de Ciências Agrárias e Veterinárias - UNESP, Campus de Jaboticabal, SP, em área experimental com o solo LVef, $1 / 16$ Hectare, Produtividade média de $375,38 \mathrm{~kg}$.

(Continua)

\begin{tabular}{|c|c|c|c|c|c|c|c|c|c|c|}
\hline & Mão- & de-obra & & & & Máquir & as e implemer & & & \\
\hline Item & Comum & Tratorista & $\begin{array}{c}\text { Trator } \\
60 \mathrm{cv}\end{array}$ & $\begin{array}{c}\text { Trator } \\
75 \mathrm{cv}\end{array}$ & $\begin{array}{c}\text { Grade } \\
\text { Nivelador } \\
\text { a }\end{array}$ & $\begin{array}{c}\text { Semeador } \\
\text { a } \\
2 \text { linhas }\end{array}$ & $\begin{array}{c}\text { Pulverizador } \\
3001\end{array}$ & $\begin{array}{c}\text { Desbastador } \\
\text { com lâmina } \\
\text { em V }\end{array}$ & $\begin{array}{c}\text { Colhedora } \\
\text { Automotri } \\
\mathrm{z} \\
117 \mathrm{cv} \\
\end{array}$ & $\begin{array}{l}\text { Custo } \\
\text { Horário } \\
\text { de Oper }\end{array}$ \\
\hline Operação & & & & & & & & & & \\
\hline $\begin{array}{c}\text { Aplicação de } \\
\text { herbicida }\end{array}$ & 0,38 & 0,25 & 0,25 & & & & 0,25 & & & \\
\hline $\begin{array}{c}\text { Rebaixamento } \\
\text { vegetal }\end{array}$ & & 0,13 & 0,13 & & & & & & & \\
\hline Gradagem leve & & 0,25 & & 0,25 & 0,25 & & & & & \\
\hline $\begin{array}{l}\text { Aplicação do } \\
\text { biossólido }\end{array}$ & 3,33 & & & & & & & & & \\
\hline Gradagem leve & & 0,08 & & 0,08 & 0,08 & & & & & \\
\hline Sulcamento & & 0,19 & 0,19 & & & 0,19 & & & & \\
\hline Adubação mineral & 0,25 & & & & & & & & & \\
\hline Semeadura & 0,15 & 0,15 & 0,15 & & & 0,15 & & & & \\
\hline Desbaste & 0,50 & & & & & & & 0,50 & & \\
\hline
\end{tabular}


TABELA 1 - Coeficientes Técnicos e Custo Horário de Operação do Milho de Verão, Preparo Reduzido de Solo, Experimento instalado no ano agrícola 2002/2003 na Fazenda de Ensino e Pesquisa da Faculdade de Ciências Agrárias e Veterinárias - UNESP, Campus de Jaboticabal, SP, em área experimental com o solo LVef, 1/16 Hectare, Produtividade média de $375,38 \mathrm{~kg}$.

(Conclusão)

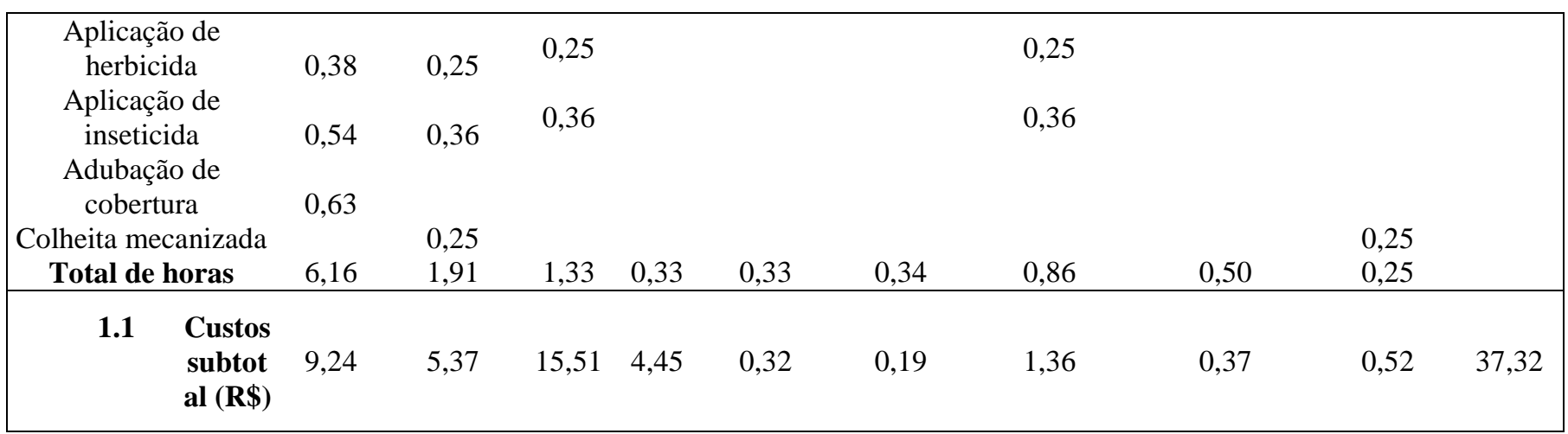

Fonte: Dados da pesquisa (2006).

Apesar destes gastos, a aplicação de lodo de esgoto como principal fonte de adubação permitiu que se atingissem níveis positivos de rentabilidades efetiva e total, tal como mostra a tabela 3 com os dados de receita, COE, COT, RE e RT.

Isso se deve aos preços pagos e recebidos pelos produtores de milho naquele ano e também à alta produtividade da cultura. Com a maior disponibilidade de nutrientes no solo decorrente da aplicação de lodo de esgoto, pode ocorrer o melhor desenvolvimento da planta e conseqüentemente maior produtividade das culturas (MELO; MARQUES, 2000).

TABELA 2 - Coeficientes Técnicos e Custos de Produção do Milho de Verão, Preparo Reduzido de Solo, Experimento instalado no ano agrícola 2002/2003 na Fazenda de Ensino e Pesquisa da Faculdade de Ciências Agrárias e Veterinárias - UNESP, Campus de Jaboticabal, SP, em área experimental com o solo LVef, 1/16 Hectare, Produtividade média de $375,38 \mathrm{~kg}$.

\begin{tabular}{|cccccc|}
\hline Material consumido & Especificação & Quantidade & Unidade & Preço (R\$) & Custo (R\$) \\
\hline Semente & Agromen 3150 & 2,5 & $\mathrm{~kg}$ & 3,92 & 9,8 \\
Fertilizante & Cloreto de potássio & 3,94 & $\mathrm{~kg}$ & 0,89 & 3,51 \\
Herbicida & Siptran & 0,25 & 1 & 9,26 & 2,32 \\
Herbicida & Sanson 40 SC & 0,06 & 1 & 104 & 6,24 \\
Herbicida & Diuron 500 SC & 0,63 & $\mathrm{ml}$ & 13,89 & 0,01 \\
Herbicida & Sanachem 720 SC & 0,63 & $\mathrm{ml}$ & 14,88 & 0,01 \\
Inseticida & Fastac 100 & 9,38 & $\mathrm{ml}$ & 42,45 & 0,13 \\
Inseticida & Nomolt 150 & 3,13 & $\mathrm{ml}$ & 131,97 & 1,24 \\
$\mathbf{1 . 1 . 1 \quad \text { Custos subtotal }}$ & & & & $\mathrm{R} \$ 23,25$ \\
Custo Operacional Efetivo (COE) & (C. H. de Operação +Mat.) & & & $\mathrm{R} \$ 60,57$ \\
Depreciação de máquinas e & & & & $\mathrm{R} \$ 7,61$ \\
equipamentos & & & & $\mathrm{R} \$ 7,49$ \\
Juros sobre o capital investido & & & & $\mathrm{R} \$ 75,67$ \\
Custo Operacional Total (COT) & (COE+ Depreciação +Juros) & & & \\
\hline
\end{tabular}

Fonte: Dados da pesquisa (2006). 
TABELA 3 - Produtividade, preço de venda, receita, custo operacional efetivo (COE), custo operacional total (COT) e rentabilidade efetiva e total do milho de verão adubado com lodo de esgoto.

\begin{tabular}{|cccccc|}
\hline Produtividade & $375,38 \mathrm{~kg}$ & \multicolumn{2}{c|}{ Custos } & \multicolumn{2}{c|}{ Rentabilidades: } \\
Preço de venda & $\mathrm{R} \$ 0,31 / \mathrm{kg}$ & $\mathrm{COE}$ & $\mathrm{R} \$ 60,57$ & Efetiva (R-COE) & $\mathrm{R} \$ 55,80$ \\
Receita & $\mathrm{R} \$ 116,37$ & $\mathrm{COT}$ & $\mathrm{R} \$ 75,67$ & Total (R-COT) & $\mathrm{R} \$ 40,70$ \\
\hline
\end{tabular}

Fonte: Dados da pesquisa (2006).

Rocha (1998) sugere que, como feito nesse estudo, o lodo venha a ser usado como complemento da adubação industrial, reduzindo a utilização de fertilizantes químicos e, consequentemente o custo de adubação.

Sendo rentabilidade econômica a diferença entre receita e custos de produção, com a queda dos custos, vem o aumento da rentabilidade desde que a receita seja mantida. Para o cultivo de milho no ano agrícola 2002/2003, adubado com lodo de esgoto, obteve-se produtividade média de 375,38 kg e renda de $\mathrm{R} \$ 116,37$. Dessa forma, a cultura obteve rentabilidade efetiva de $\mathrm{R} \$ 55,80$ e rentabilidade total de $\mathrm{R} \$ 40,70$.

Esses resultados mostram que a aplicação de lodo de esgoto na agricultura pode ser alternativa das mais promissoras, devido a sua sustentabilidade ambiental e econômica (ROCHA; SHIROTA, 1999). As questões sanitárias podem ser superadas por meio de manejo adequado do lodo fresco ou através de processos que o desinfestem e o estabilizem. Contudo, a questão econômica é mais complexa, porque há uma série de custos a serem mensurados, em contraste com os benefícios econômicos que cada biossólido pode porporcionar (CORRÊA; CORRÊA, 2001).

\section{CONCLUSÃO}

Os resultados de rentabilidade efetiva $(\mathrm{R} \$ 55,80)$ e rentabilidade total $(\mathrm{R} \$ 40,70)$ para o cultivo de milho de verão no ano agrícola 2002/2003, adubado com lodo de esgoto permitem concluir que a aplicação de lodo de esgoto é economicamente rentável uma vez que atinge lucratividade tanto no médio como no longo prazo.

\section{REFERÊNCIAS}

ANDREOLI, C. V.; LARA, A. I.; FERNANDES, F. Reciclagem de biossólidos: transformando problemas em soluções. Curitiba: Sanepar; Finep, 1999. 288p.

BEZERRA, F. B. et al. Lodo de esgoto em revegetação de área degradada. Pesquisa Agropecuária Brasileira, Brasília, v.41, n.3, p.469-476, mar. 2006.

CORRÊA, R.S.; CORRÊA, A.S. Valoração de biossólidos como fertilizantes e condicionadores de solos. Sanare, Curitiba, v.16, n. 2, p 49-56, 2001.

GUEDES, M. C. ET al. Propriedades químicas do solo e nutrição do eucalipto em função da aplicação de lodo de esgoto. Revista Brasileira de Ciência do Solo, 30:267-280, 2006.

LEMAINSKI, J.; SILVA, J.E. da. Utilização do biossólido da CAESB na produção de milho no Distrito Federal. Revista Brasileira de Ciência do Solo, v.30, p.741-750, 2006.

MATSUNAGA, M.et al. Metodologia do custo de produção utilizada pelo IEA. Agricultura em São Paulo, São Paulo, v.23, t.1, p.123-139, 1976. 
MELO, W.J.; MARQUES, M.O. Potencial do lodo de esgoto como fonte de nutrientes para as plantas. In: BETTIOL, W.; CAMARGO, O. A. (Ed.). Impacto ambiental do uso agrícola do lodo de esgoto . Jaguariúna: Embrapa Meio Ambiente, 2000. p.109-141.

REIS, R. P.; TAKAKI, H. R. C.;REIS, A. J. Como calcular o custo de produção. Lavras: UFLA, 1999.15p.

REZENDE, B. L. A. et al. Custo de produção e rentabilidade da alface crespa, em ambiente protegido, em cultivo solteiro e consorciado com tomateiro, Jaboticabal, Estado de São Paulo. Informações

Econômicas, v.35, n.7, p.42-50, 2005.

ROCHA, M.T., (1998). Utilização de lodo de esgoto na agricultura: um estudo de caso para as bacias hidrográficas dos rios Piracicaba, Capivari e Jundiaí. Piracicaba. 1998. (Dissertação/Mestrado). Escola Superior de Agricultura “Luiz de Queiroz”, Universidade de São Paulo. Piracicaba.

SHIROTA, R.; ROCHA, M.T., Disposição final de lodo de esgoto. Revista de estudos ambientais, v.1, n.3, set/dez 1999.

TRANNIN, I. C. B; SIQUEIRA, J.O.; MOREIRA, F.M.S. Avaliação agronômica de um biossólido industrial para a cultura do milho. Pesquisa Agropecuária Brasileira, Brasília, v.40, n.3, p.261-269, mar. 2005. 
